\title{
La violencia en el Triángulo Norte de Centroamérica: una realidad que genera desplazamiento*
}

\author{
Violence in the Northern Triangle of Central \\ America: a Reality Generating Displacement
}

\author{
Everardo Víctor Jiménez ${ }^{* *}$
}

Recibido: 13 de mayo de 2015

Aprobado: 9 de marzo de 2016

Disponible en línea: 30 de junio de 2016

\section{Resumen}

El trabajo que aquí se presenta, basado en una revisión de la literatura de lo que se ha producido en los últimos años, trata el fenómeno de la violencia en el Triángulo Norte de Centroamérica como un generador de desplazamiento forzado de la población. En primer lugar, según varios autores, se establecerán criterios válidos, con el fin de construir un concepto más amplio y más claro de la violencia, que a su vez permite la captura de todas las dimensiones de su manifestación en la región centroamericana. Los factores que fomentan esta violencia serán considerados más adelante, en relación con aspectos sociales, culturales o políticos. En toda esta alarmante ola de violencia, algunos de los actores principales son notorios, por ejemplo bandas como las maras y traficantes de droga. La violencia generada por estos actores, junto con la violencia estructural soportada por las

\section{Abstract}

The work presented here, based on a literature review of what has been produced in recent years, treats the phenomenon of violence in the Northern Triangle of Central America as a generator of forced displacement among the population. First, according to various authors, valid criteria will be set in order to construct a broader and clearer concept of violence, which in turn allows capturing all the dimensions of its manifestation in the Central-American region. Factors fostering this violence will be later considered, related to social, cultural or political aspects. In all this alarming wave of violence, some main actors are notorious, e.g. gangs like the "Maras" and drug traffickers. Violence generated by these actors, together with the structural violence borne by CentralAmerican Northern Triangle societies, lead to displacement of the population. Therefore, it is

doi:10.11144/Javeriana.papo21-1.vtnc

* Artículo de revisión.

** Estudiante de Doctorado en Derechos Humanos de la Universidad de Deusto (España). Licenciado en Filosofía, licenciado en Teología, magíster en Educación y magíster en Ciencias Sociales. Docente en la Facultad de Humanidades y Comunicación de la Universidad Centroamericana (Managua, Nicaragua). Director general de Fe y Alegría Nicaragua. Correo electrónico: ni.director@feyalegría.org 
sociedades centroamericanas del Triángulo del Norte, provoca el desplazamiento de la población. Por tanto, es imperativo encontrar soluciones para hacer frente a esta realidad que está creando tal expulsión de la población, que trata de escapar de la violencia y está a menudo indefensa frente a ella.

\section{Palabras clave}

violencia; maras; traficantes; víctimas de la violencia; desplazamiento forzado

\section{Cómo citar este artículo:}

Jiménez, E. V. (2016). La violencia en el Triángulo Norte de Centroamérica: una realidad que genera desplazamiento. Papel Político, 21(1), 167-196. http://dx.doi.org/10.11144/ Javeriana.papo21-1.vtnc imperative to find solutions to face this reality that is creating such banishment among the population who seeks to escape violence and is often defenseless against it.

\section{Keywords}

violence; gangs; violence victims; drug traffickers; forced displacement 


\section{Introducción}

La violencia que se vive en el territorio centroamericano es alarmante. Ella continúa provocando una trágica movilización humana tanto interna como externa que recuerda el tiempo de las guerras civiles de la década de 1980. La Organización Mundial de la Salud (OMS) señala que, cuando en un país la tasa de homicidios por cada 100 ooo habitantes es mayor de 10 personas, se vive en ese país una verdadera epidemia de homicidios. A excepción de Costa Rica y Nicaragua, el resto de las naciones centroamericanas vive tal epidemia debido a que sobrepasan ese rango: Panamá (20-30), El Salvador (mayor de 30), Guatemala (mayor de 30) y Honduras (mayor de 30) (Centro Regional de Servicios para América Latina y el Caribe, 2013).

Según el Informe regional de desarrollo humano 2013-2014 (2013), los homicidios en Latinoamérica van en aumento y superan la media internacional de 2000-2010; los homicidios registrados han crecido en 12 \% y a quienes más afecta es a la población masculina y juvenil entre los 10 y 25 años que vive en las ciudades de la región (Centro Regional de Servicios para América Latina y el Caribe, 2013, párr. 2). De los 18 países de la región analizados en este informe, 11 tienen niveles altos de homicidio, pues superan los 20 homicidios por cada 100 ooo habitantes.

La Universidad Nacional Autónoma de Honduras y el Instituto Universitario de Democracia, Paz y Seguridad (2013) señalan que en Honduras 78.8 \% de las víctimas de la violencia que sacude al país son personas entre los 15 y 44 años, la mayoría hombres (90.6\%). Según dicho informe mueren al día por violencia 19 personas, las cuales suman al mes 563. El 83.3 \% de los homicidios son cometidos utilizando armas de fuego. Según informes policiales, se desconoce el motivo del delito. Por otra parte, $13.1 \%$ de ellos es por ajuste de cuentas, o sea, homicidios que son ejecutados por sicarios. De 2004 a 2013 han perdido la vida en Honduras por la violencia 47862 personas, lo cual representa un promedio de crecimiento anual de 232.8 \% (Observatorio de la Violencia, 2013).

En este informe, se evidencia la impunidad que existe ante los homicidios, pues no se identifica y persigue a sus responsables. Ello también evidencia una debilidad del sistema judicial y de las autoridades garantes de la seguridad de los ciudadanos, lo cual lleva a las personas a desconfiar de dichas instituciones y a percibir que la inseguridad es parte de su realidad cotidiana, tanto así que por esa idea de inseguridad $15 \%$ de los hondureños y $16 \%$ de los salvadoreños han expresado deseos de cambiar de barrio o colonia debido al temor que sienten por la delincuencia que sufre el país (Centro Regional de Servicios para América Latina y el Caribe, 2013).

Lo anterior se confirma en estudios realizados por el Instituto Universitario de Opinión Pública de la Universidad Centroamericana José Simeón Cañas de El Salvador durante 2012 y 2014. Para 2012, 27.2 \% de los entrevistados deseaba migrar y $37.1 \%$ apuntaba como el principal problema por enfrentar el de la delincuencia/inseguridad (Universidad 
Centroamericana José Simeón Cañas, Instituto Universitario de Opinión Pública, 2015). Dos años más tarde (2014), 33 \% de los entrevistados deseaba migrar o irse del país y $50.7 \%$ de la población consideraba que el principal problema por enfrentar en El Salvador era la delincuencia/inseguridad. Cabe también señalar de este informe que $4.6 \%$ de los entrevistados ha cambiado de vivienda debido a amenazas recibidas y $8 \%$ dijo también que algún familiar tuvo que salir del país debido a la misma situación. Señala este informe que, "aunque porcentualmente estos hechos pueden parecer menores, el desplazamiento forzado interno y transnacional debido a la delincuencia parece haberse duplicado respecto a los últimos dos años” (Universidad Centroamericana José Simeón Cañas, Instituto Universitario de Opinión Pública , 2015, p. 3). Más adelante en el resumen se afirma:

La delincuencia se mantiene como la principal fuente de preocupación pública, al tiempo que han crecido las percepciones de que la criminalidad aumentó en 2014. La victimización por delincuencia común también creció, además de los que reportan haber sufrido desplazamiento forzado por la amenaza de grupos delincuenciales. Este último fenómeno parece irrumpir como parte de las nuevas expresiones de la criminalidad prevalecientes en el país, asociadas al mayor control territorial de los grupos criminales (p. 7).

\section{Hacia una idea de violencia}

La violencia en Centroamérica preocupa tanto a los Gobiernos como a la sociedad en general y, para encontrar una salida, los Estados han querido dar respuestas que lamentablemente no han dado los frutos deseados. ${ }^{1}$ Sin embargo, a pesar de ello, no ha sido posible contenerla y esta ha ido aumentando en la última década.

Actualmente, la violencia sigue siendo el denominador común en la región, pero se manifiesta de forma diferente de la segunda mitad del siglo XX. Ahora se trata de delincuencia y crimen sin fines ideológicos. No se persigue el poder político, sino beneficios particulares (personales u organizacionales). Semejante violencia compromete seriamente la paz y la gobernabilidad de la región, con los consiguientes efectos políticos: tiene un carácter esencialmente urbano, comprende todo tipo de conflictos sociales y económicos y, además, se funde con grandes amenazas como el tráfico de drogas o de armas (Fernández, 2006).

\footnotetext{
${ }^{1}$ Para combatir a las maras, se implementó la política de mano dura. La mano dura tuvo sus inicios en El Salvador en julio de 2003 y con ella se pretendía llevar a la cárcel a todo joven que tuviera un vínculo con las maras, ya sea porque llevaba tatuajes, ya sea porque demostrara públicamente su vinculación con estas. Posteriormente, la misma política fue declarada inconstitucional por violar muchos derechos humanos. Pero pronto apareció una nueva ley para atacar a los mareros conocida como Mano Súper-Dura, la cual, para ser implementada, requería del individuo un comportamiento delincuencial activo. Muy pronto, otros países de Centroamérica implementaron esta ley, aunque en Honduras le dieron el nombre de Cero Tolerancia y en Guatemala de Plan Escoba.
} 
Aunque pudiéramos señalar que para el caso concreto del Triángulo Norte de Centroamérica la violencia no es solo un fenómeno urbano, ya que esta se ha extendido de la ciudad al campo o a los departamentos fuera de la capital de estos países, sobre todo se ha propagado a lugares empobrecidos del Triángulo Norte de Centroamérica, los cuales están fuera de control por parte del Estado.

La OMS describe la violencia como

el uso deliberado de la fuerza física o el poder, ya sea en grado de amenaza o efectivo, contra uno mismo, otra persona o un grupo o comunidad, que cause o tenga muchas probabilidades de causar lesiones, muerte, daños psicológicos, trastornos del desarrollo o privaciones (2012, p. 5).

Continuando con nuestra reflexión sobre la violencia, Fernández (2006) sugiere que la violencia hay que analizarla teniendo presente varias perspectivas:

Primero, el predominio de la cultura de violencia en determinados territorios; segundo, la percepción de seguridad o distancia entre la violencia real (frecuentemente minusvalorada) y la sensación de violencia en la población; y, tercero, el consenso (o, mejor, la falta de él) por parte de las instituciones y otras organizaciones acerca de los tipos de violencia que representan la mayor amenaza y cuál es la manera de contenerlos (pp. 6o-61).

Esta autora, además, señala que entre los factores estructurales ligados a la violencia se encuentran la pobreza o mejor dicho el empobrecimiento y la desigualdad social, la ingobernabilidad de territorios que también se ve reflejada en la poca capacidad para que se cumplan las leyes, el acceso progresivo de armas de fuego ligado a ciertos patrones culturales para demostrar fuerza y, finalmente, el poco acceso a la educación y al trabajo, lo cual hace muy susceptible a la población, sobre todo a los jóvenes, para implicarse en la delincuencia a cambio de obtener dinero o cierto estilo de vida que les "dé mayor prestigio social” al cual no pudieran acceder desde su situación de pobreza (Fernández, 2006, p. 61).

Para Machado (2011), la violencia

articula, segundo uma gramática própria, uma série de enunciados - relatos, interpretações, sugestões, avaliações, etc.- que expressam um debate a respeito de um amplo conjunto de práticas ilícitas, as quais, dependendo dos contextos, podem envolver desde a simples incivilidade até a extrema crueldade, passando por variáveis graus de violência física² (p. 70).

${ }^{2}$ Articula, de acuerdo con su propia gramática, una serie de enunciados - relatos, interpretaciones, sugerencias, críticas, etc.- que expresan un debate sobre una amplia gama de prácticas ilegales, que, dependiendo del 
La persona que sufre por la violencia se siente constantemente amenazada y vive en una sociabilidad violenta que se reproduce por medio de actividades llevadas a cabo por actores competentes que conocen esa forma de vida en la cual se van conduciendo adecuadamente (Machado, 2011). Sus portadores típicos son los bandos de traficantes, los delincuentes comunes, las maras o pandillas, entre otros actores. Lo anterior quiere decir que la sociología de la sociabilidad de la violencia es necesaria para comprender la violencia, una violencia que en muchos países ha llevado a una guerra sin cuartel contra los criminales y mareros, pero no ha dado buenos resultados.

Siguiendo la discusión que tenemos sobre la violencia, González (2013) la entiende

como el uso de la fuerza por parte de sujetos, grupos o instituciones aplicada a otros sujetos, grupos o instituciones con el propósito de obtener algún beneficio o ganancia en contra de su voluntad o de su consentimiento autónomo. Esta dinámica, además de modificar, transformar o mantener por la fuerza una serie de condiciones, actividades, procesos o comportamientos, pone de manifiesto, concreta y simbólicamente el poder, las intenciones y convicciones del agente de la violencia (p. 172).

Según lo que este autor entiende por violencia, distingue en ella dos dimensiones: la violencia estructural u objetiva y la violencia subjetiva.

La violencia estructural es la utilización de medios coercitivos para la subordinación de una clase por parte de otra con la finalidad de obtener una ganancia material, proceso que toma forma en una explotación del humano por el humano y, por ende, requiere de la dominación como una condición sine qua non de las relaciones sociales de producción (p. 173).

Por el contrario, la violencia subjetiva "se refiere a la violencia ejercida, física e ideológicamente, por los agentes sociales e instituciones, relacionada con la criminalidad, la discriminación, los fundamentalismos, el racismo y otras expresiones de este corte” (p. 174).

Otra definición de violencia es la que nos proporcionan Gutiérrez, Magdaleno del Río y Yáñez (2010), quienes identifican algunos referentes comunes que permiten evidenciar la violencia en la realidad:

Es un acto que implica el uso de la fuerza física, moral o psicológica que ocasiona daños, en el cual participan y se relacionan individuos, grupos, instituciones o el Estado. Este tipo

contexto, pueden implicar desde la simple falta de civismo a crueldad extrema, a través de diversos grados de violencia física. 
de acciones tienen consecuencias directas en los actores involucrados [sufrimiento, dolor, incapacidad física, muerte, etc.] al igual que en la sociedad en la que se suscitan (p. 107).

Para Rojas (2008), la violencia afecta la integración social, pero también tiene repercusiones económicas, políticas y sociales:

La violencia deteriora la integración social; rompe el tejido social; impacta negativamente el crecimiento y desarrollo económico. Ahuyenta la inversión nacional y en especial la extranjera. Erosiona la legitimidad del Estado y aumenta la desconfianza de la ciudadanía; y reduce el apoyo a la democracia. Sin seguridad no hay predictibilidad y las incertidumbres aumentan. Sin seguridad no hay desarrollo humano. Los costos de la seguridad individual y de las sociedades aumentan, con ellos la inequidad y la fragmentación de las ciudades. La violencia aumenta la ingobernabilidad, debilita la democracia, incrementa la desconfianza y genera las condiciones para violaciones de los derechos humanos (p. 11).

Según un estudio realizado por Hiskey, Malone y Orcés (2014) para el Barómetro de las Américas:

La victimización, así como el miedo al delito están significativamente relacionados con las intenciones de migrar... Del mismo modo, la experiencia personal con la corrupción aumenta significativamente la probabilidad de que un individuo contemple salir de su país... Estos hallazgos indican que, además de sus otras consecuencias trágicas, la ola de violencia que afecta actualmente a gran parte de América Central también parece estar contribuyendo a un mayor número de personas que buscan salir del país (p. 7).

Es decir que la violencia y la delincuencia pueden ser consecuencias probables de las migraciones, y no solo las causas económicas o familiares, o dicho de otra manera, la violencia y la delincuencia pueden motivar a migrar y más cuando se tiene miedo o se es víctima y cuando a la vez se respira por parte del afectado un nivel de inseguridad. Se puede sostener consecuentemente que es muy probable que la violencia en el Triángulo Norte de Centroamérica sea una de las causas principales del desplazamiento de muchas personas hacia Norteamérica, principalmente hacia México y los Estados Unidos, ya que son, a su vez, los tres países del Triángulo Norte los que tienen los más altos niveles de delincuencia y violencia en la región y son al mismo tiempo los que tienen el mayor número de migrantes en la región (Hiskey, Malone y Orcés, 2014).

Revertir esa situación no solo es llevar adelante una lucha contra los criminales, sino que son necesarias "acciones públicas que transformen rehenes de la violencia urbana en ciudadanos plenos" (Fortuna, 2012, p. 119). Luchar contra el crimen organizado y la violencia 
es un reto permanente, que presenta un doble desafío a la sociedad: asegurar el pleno acceso de todo ciudadano a los derechos humanos económicos, sociales, culturales, civiles, al mismo tiempo que requiebra el poder de intimidación y corrupción de redes delictivas (p. 119).

A partir de las ideas anteriores sobre la violencia, proponemos para nuestro trabajo la definición que desde 2002 diera la OMS, que entiende por violencia:

El uso deliberado de la fuerza física o el poder, ya sea en grado de amenaza o efectivo, contra uno mismo, otra persona o un grupo o comunidad, que cause o tenga muchas probabilidades de causar lesiones, muerte, daños psicológicos, trastornos del desarrollo o privaciones (p. 5).

Consideramos que esta definición, a pesar de tener limitaciones como cualquier otra definición, es mucho más extensa, pues no solo hace referencia al uso de la fuerza física o a la violencia que ejercen quienes tienen el poder, sino que se dirige a las consecuencias de ejercerla, que van desde lesiones, muerte, daños psicológicos, trastornos o privaciones. Y esas consecuencias pueden ser en lo personal, en las relaciones y en lo comunitario o en lo social (OMS, 2002).

Con la definición dada por la OMS, podemos inferir que, en el caso del Triángulo Norte de Centroamérica, la violencia ejercida sobre la población civil acarrea, en muchos casos, desplazamiento forzado. Es decir que la violencia que actualmente se experimenta en el Triángulo Norte de Centroamérica genera en la población desplazamiento interno como transnacional. Por ello, pensamos que esta definición de violencia es pertinente para entenderla mejor en la región centroamericana.

\section{Factores que fomentan la violencia}

En este apartado, trataremos de situarnos frente a lo que varios autores sostienen que son factores fomentadores de la violencia. Concretamente, abordaremos la segregación, el mercado de la droga, la masculinidad, el problema del alcohol, el tema de la corrupción y el de la impunidad; pasaremos luego a señalar los Estados débiles como un factor que facilita la violencia; continuaremos con la inequidad, el desempleo y la falta de oportunidades, así como otros factores que facilitan la violencia; y proseguiremos el apartado refiriéndonos a la tenencia de las armas y a las deportaciones en la región centroamericana como otros facilitadores de la violencia. Culminaremos toda esta clasificación de factores con un modelo teórico sobre la violencia, de los muchos que hay, para fines de teorización e investigación, como el modelo ecológico propuesto por la OMS.

\section{Factores sociales}

Para Briceño-León (2007), existen tres situaciones concretas que fomentan la violencia o la pueden aumentar: "La segregación urbana que produce ciudades divididas y el mercado local de la droga; y una de tipo cultural: la masculinidad” (p. 561). 


\section{La segregación y la densidad urbana}

Es un hecho constatable que en los últimos años casi todas las ciudades latinoamericanas crecieron, se fueron urbanizando debido a la migración del campo a ciudad y en cada una de ellas los recién llegados ocuparon las afueras de ellas para vivir. Estas personas que arribaron a las capitales latinoamericanas eran, en general, personas desempleadas, campesinos sin tierra, desplazados internos por la guerra, personas con bajos niveles de escolaridad, que lo que buscaban eran nuevos horizontes para ellos y para sus familiares. Los nuevos residentes de las ciudades ocuparon las zonas marginales o que estaban en las afueras y las urbanizaron, lucharon por tener los servicios básicos (luz, agua potable, alcantarillados, carreteras, etc.), pero las zonas ocupadas fueron lugares de residencia o dormitorios que no llegaron nunca a convertirse en zonas industrializadas.

Esto implica que muchos de los nuevos habitantes urbanos tuvieran muchas dificultades para encontrar tanto un empleo como un lugar donde vivir... buscaron entre los intersticios de la propiedad de la tierra un espacio que hubiese dejado la urbanización formal y allí procedieron a construir su vivienda; y se emplearon a sí mismos en lo que hoy llamamos sector informal (Briceño-León, 2007, p. 562).

Cabe destacar que esas zonas poco a poco se fueron mejorando con la introducción de servicios básicos y con la mejora de los materiales de las viviendas, pero esa situación de mejora cambió hacia inicios de la década de 1970, pues la pobreza aumentó y ello trajo consigo tres impactos, según Briceño-León (2007), que fomentaron la violencia: primero, las viviendas comenzaron a deteriorarse, era requerido su mantenimiento, pero la situación económica no era buena para hacerlo; segundo, en esas zonas, se incrementó la población por los hijos y los nietos de los primeros que ocuparon esos espacios; tercero, al ser un urbanismo sin planificación, se vuelve con el tiempo muy denso en población y, a la vez, se vuelven territorios porosos y de fácil acceso para los criminales, pero no así para la policía (p. 562).

\section{La inequidad, el desempleo y la falta de oportunidades}

Se ha sostenido muchas veces que la violencia que se vive actualmente tiene sus raíces en los conflictos armados que se vivieron en la década de 1980 en la mayoría de los países centroamericanos y por las secuelas que marcaron la sociedad posguerra. Según esta tesis, desde la guerra se explicaría el fenómeno de la violencia. Para Cardenal (2008), más que la guerra, lo que genera violencia en Centroamérica es la desigualdad, es decir que lo que influye verdaderamente en el crimen actual es "la desigualdad" (p. 69). Para ella, no existe una relación directa entre la guerra y la violencia actual que se vive en la región centroamericana, principalmente en el conocido Triángulo Norte de Centroamérica. Esta autora 
propone abordar la violencia desde un enfoque integral en el que se tomen en cuenta "factores individuales, contextuales, sociales y económicos" (p. 69) para comprenderla mejor.

Actualmente, lo que se constata en las estadísticas es que los departamentos que fueron más afectados por la guerra no son los más violentos; "no hay una gran coincidencia entre la geografía de la guerra y la geografía del crimen en El Salvador y Guatemala” (p. 81). Es decir que, al contrario de lo que algunos piensan, los departamentos que estuvieron expuestos directamente a la guerra son los que cuentan con menores índices de homicidio y de delito. Recalca esta autora que en el ámbito de los países centroamericanos tampoco parece que la educación, la pobreza o el desempleo sean factores explicativos de las tasas de homicidio; el único factor que parece tener un alto poder explicativo de las tasas de homicidio por países es la desigualdad.

En la misma perspectiva de Cardenal, la investigadora De León (2008) sostiene que la violencia es fruto de la inequidad y la exclusión. "La violencia es productor del impacto sicológico y pérdida del tejido social causado por los diversos conflictos armados vividos en la región; de la debilidad institucional y de la ausencia de políticas públicas incluyentes y equitativas" (p. 71). Pero Cardenal (2008) se diferencia de De León cuando sostiene que la violencia es causada por los conflictos armados.

América Latina es una región altamente violenta e insegura y en ella Centroamérica ha pasado por guerras sangrientas y, aunque se firmaron acuerdos de paz para sentar las bases de una sociedad democrática, ello no ha posibilitado una mejoría de las condiciones de vida de sus habitantes. Es de destacar la consolidación de la democracia, pero aún hay muchas debilidades. Aparte de lo anterior, en Latinoamérica se vive una desigualdad económica y una exclusión social, en una palabra: inequidad. A ello hay que sumarle la debilidad institucional y la presencia del crimen organizado y del narcotráfico. Esto genera un círculo vicioso entre violencia, desigualdad y exclusión.

Como consecuencia de esa inequidad, los jóvenes son las principales víctimas del sistema y de la violencia. La juventud centroamericana vive en espacios deprimidos, de conflictos, cargados de violencia y de exclusión, lo cual genera frustración en esta población. En un ambiente de privación de servicios y recursos, los jóvenes buscan llenar esos vacíos y obtienen ciertos beneficios por medio de la violencia.

\section{Factores culturales}

El Centro Regional de Servicios para América Latina y el Caribe (2013) señala como facilitadores del delito y la violencia el consumo del alcohol, la corrupción y la impunidad, factores que abordaremos a continuación. Tanto la corrupción como la impunidad pueden fomentar la violencia. En nuestra sociedad tanto una como la otra son comunes y se evidencian en muchos comportamientos y en diversos grupos de la sociedad (empresariales, políticos, trabajadores estatales, policía y la sociedad en general). 


\section{El mercado local de la droga}

La droga aumenta la delincuencia y, en consecuencia, los homicidios. Son cantidades enormes de droga las que se producen y distribuyen. Ha habido una guerra contra las drogas, la cual ha resultado infructuosa. Este supuesto combate ha hecho que las redes criminales se hayan dispersado a la vez que se ha aumentado la violencia y sus diversas manifestaciones.

Entrar en el mercado de la droga se vuelve atractivo y es una alternativa para muchas personas por los grandes beneficios que se pueden obtener de su comercialización. Pero para hacer el negocio más rentable, es necesario quitar del paso a otros que la distribuyen. De ahí que surge una batalla campal por eliminar de en medio a otros distribuidores y para ampliar el territorio donde se comercializa la droga.

$\mathrm{Al}$ ser de naturaleza ilícita, la droga se mueve a través de canales también ilícitos, sumergidos, lo cual genera una dinámica de violencia y criminalidad. Con la producción y su posterior distribución, se pueden proveer recursos a las bandas criminales, se corrompe a las autoridades, se puede generar el lavado de dinero y se puede corromper la naturaleza humana. Este ilícito genera inmensas rentas, motiva a muchos jóvenes para que se sumen a cometer actos ilícitos en las organizaciones a costa de obtener alguna jugosa renta. El Centro Regional de Servicios para América Latina y el Caribe (2013) señala que, "en el caso de Centroamérica, se encuentra una correlación entre las zonas claves para el tráfico y las altas tasas de homicidio, especialmente en Guatemala y Honduras” (p. 33).

La violencia generada por el mercado de la droga tiene altas cuotas de impunidad. Existe la percepción bastante generalizada de que quien comete delitos en este campo difícilmente irá a prisión. Las ganancias del mercado de la droga son astronómicas y ha conducido a la corrupción de policías, fiscales y jueces con lo cual causa un gran daño en las instituciones que han de velar por la justicia (Briceño-León, 2007). En general, se puede decir que la droga fomenta la violencia.

\section{El consumo del alcohol}

El consumo del alcohol está sin duda asociado con la violencia y todas sus manifestaciones. Según estudios del Centro Regional de Servicios para América Latina y el Caribe (2013) casi 6o \% de los que están en las cárceles cometieron delitos cuando habían consumido alcohol. Es cierto que no todas las personas que consumen alcohol son violentas, pero, al provocar desinhibición, en algunas crea el efecto de ser más comunicativas y extrovertidas y, a la vez, más agresivas.

En palabras del Centro Regional de Servicios para América Latina y el Caribe (2013): "La ingesta de alcohol se asocia a diversos tipos de violencia, sobre todo al delito común y a la violencia de género" (p. 34). Al final, se cometen homicidios al combinarse dos factores: estar ebrio y portar armas. 


\section{La cultura de la masculinidad}

Para Briceño-León (2007), la violencia es propia de los hombres, ya que, según revelan muchas estadísticas, son ellos quienes la ejercitan y quienes la sufren; en proporción, son más los hombres quienes se ven afectados por la violencia que las mujeres, excepto en la violencia de género, que la sufren las mujeres, y que es ejercida por los hombres.

Esa diferencia tan acentuada puede atribuirse a

una cultura de la masculinidad que favorece las actuaciones violentas y la exposición al riesgo de la violencia... Los hombres actúan de una manera tal que se los diferencie de las mujeres y por eso son víctimas de la violencia (Briceño-León, 2007, p. 564).

Las mujeres evitan la violencia, mientras que los hombres desde la adolescencia deben reafirmarse en una cultura machista que los lanza al riesgo. Por tanto, para hacerse respetar como hombre ante los otros hombres, para reafirmar la identidad y la virilidad, se ven expuestos al riesgo, sobre todo en contextos de pobreza donde la violencia forma parte de la vida y donde los hombres crecen aprendiendo su dinámica (Briceño-León, 2007).

\section{Factores políticos}

Según Rojas (2008), existen algunos factores que pueden estar detrás de expresiones violentas, como la inequidad, el desempleo y las instituciones democráticas débiles. Otras manifestaciones de un Estado débil son la impunidad y la tenencia de armas sin un debido control en manos de la población civil.

\section{Los Estados débiles}

La inseguridad está ligada a debilidades del Estado y los poderes no estatales ilegales son una amenaza real. Un Estado débil se afecta a sí mismo, pero también a su población (Rojas, 2008). Un Estado débil es el mayor detonante para que se genere la inseguridad $\mathrm{y}$, en consecuencia, se aumente.

Los Estados se han enfrentado al crimen organizado para contrarrestar la violencia a través de lo que se ha llamado guerras de la globalización o nuevas guerras, que se caracterizan por ser internas, porque involucran a diversos actores internacionales y porque se llevan a cabo en zonas donde los Estados son débiles o fallidos. Estas "guerras" tienen como víctimas principales a los civiles a quienes se les violan constantemente los derechos humanos e implican un desdibujamiento de las distinciones entre guerra (normalmente definida como la violencia por motivos políticos entre Estados o grupos políticos organizados), crimen organizado (la violencia por motivos particulares, en general, el beneficio económico, ejercida por grupos organizados privados) y violaciones a 
gran escala de los derechos humanos (la violencia contra personas individuales ejercida por Estados o grupos organizados políticamente) (Rojas, 2008).

Hay que mirar las causas de la violencia, pues la violencia es un síntoma y, para atacarla, hay que ir a la causa de la enfermedad. Los factores propicios que generan condiciones para que se manifieste la violencia y el crimen organizado son la inequidad, la pobreza, la urbanización, el desempleo y la corrupción. Aquellos son mucho más posibles donde hay Estados débiles.

En zonas donde hay ausencia del Estado, surgen poderes alternativos que van imponiendo su orden y normas con la violencia. Son actores ilegales que operan en zonas protegidas por ellos mismos; allí no impera la ley más que la propia, que ejerce la violencia con toda libertad; estas zonas son espacios sin ley.

\section{La corrupción}

La corrupción es una práctica bastante común y extendida en América Latina. Muchas de las personas entrevistadas por el Centro Regional de Servicios para América Latina y el Caribe (2013) sostienen que han sido víctimas de la corrupción principalmente por agentes de la policía, lo cual genera un nivel de desconfianza en la población. Los estudios realizados evidencian una relación estrecha entre las tasas de delito y la corrupción, y es que a bajas tasas de delito hay bajas tasas de corrupción.

La corrupción es uno de los grandes males que enfrenta la sociedad latinoamericana, un mal bastante extendido al que nos podemos acostumbrar o mostrarnos indiferentes ante una conducta humana que aparente y realmente va en aumento, sobre todo, en los funcionarios públicos. La corrupción no es fenómeno nuevo, pues ha estado presente a lo largo de la historia humana, pero hoy es mucho más fácil de detectar o de sospechar.

Intentar extirpar la corrupción del mundo de la política y del Gobierno es una pretensión utópica, ya que implicaría cambiar el rumbo de la humanidad al trazar una nueva ruta que modifique el estilo de vida contemporáneo. Lo que sí es posible realizar es el fortalecimiento de la moral social, a fin de establecer principios éticos que guíen el actuar de los servidores públicos y establecer un dique que frene el mar de corrupción y dé un giro hacia un buen gobierno, en el que se abandonen las conductas basadas en antivalores (Bautista, 2009).

El fenómeno de la corrupción ha estado presente en la historia de la humanidad.

Desde siempre, los tributos, las leyes, las actividades comerciales y, en general, los términos de intercambio de bienes o servicios han sido el medio para que personas sin consideración por los intereses y la propiedad colectiva obtengan beneficios individuales en lo económico y/o social (Saiz, Mantilla y Cárdenas, 2012, p. 47). 
González (2013) compara la corrupción con una variable que puede tender a aumentar o a disminuir en una sociedad concreta. A medida que la corrupción aumenta, al mismo tiempo los conflictos sociales pueden incrementar como resultado de un mal que la gente termina repudiando y al cual se termina revelando.

Sin embargo, son muchos los funcionarios públicos, los políticos, los jueces o los empresarios que pueden ser seducidos a cometer actos de corrupción. El soborno es una de las formas más conocidas de corrupción, aunque la corrupción no se agota en este, simplemente es una de sus manifestaciones más visibles. El soborno consiste "en el pago de dinero y otros valores que deviene en la transformación de una situación política, con su código especial, en una situación mercantil, que posee su propio código" (Reisman, 1981, p. 42).

Según González (2013), un funcionario posee una conducta corrupta cuando no usa adecuadamente su autoridad, cuando hace o no hace por dinero lo que le corresponde hacer o dejar de hacer, cuando acepta sobornos o lo demanda para favorecer a una persona concreta, cuando sus actuaciones son incompatibles o destruyen "un sistema de orden público o cívico" o cuando "en su toma de decisiones" busque lucro personal, negocio, enriquecimiento o prestigios "para su familia, grupo o partido" (p. 41).

Como se afirmó, la corrupción está presente en toda sociedad y, por consiguiente, no es exclusiva de los países pobres, como algunos tienden a pensar, pero hay que reconocer que hay sociedades que se blindan mejor para resistir este mal. Sin embargo, González (2013) sostiene "que a mayor: Caos, subdesarrollo, desorientación, desintegración, dependencia del exterior, indisciplina, desigualdad, ignorancia y deshonestidad, mayor será la corrupción” (p. 45).

Se pueden considerar actos "corruptos aquellos actos que involucran una violación de ciertos deberes relativos al ámbito público con el fin de obtener beneficios privados extraposicionales" (Artavia, 2008, p. 17). El acto es corrupto según esta definición cuando un individuo que trabaja en la esfera pública viola sus deberes que han de estar regidos según ciertos parámetros éticos y el individuo transgrede la ley para sacar ventaja o beneficios privados en los ámbitos personal, familiar o político. Continúa diciendo Artavia sobre un acto corrupto:

Que no todo tipo de violación de un deber puede ser considerado un “acto corrupto”... Para ser considerado corrupto, es necesario que ese funcionario persiga algún beneficio privado extraposicional... no necesariamente... monetarios. Muchas veces se presentan bajo la forma de "regalos" o "premios", que van desde objetos de uso personal hasta la cobertura de gastos de viaje, lujosas viviendas y automóviles, o acciones negociables en la bolsa. Y, finalmente, que ese beneficio puede ser directamente disfrutado por el propio funcionario, o también cabe la posibilidad de que sea destinado a su familia, o que se presente como una contribución de campaña a su partido político (p. 16). 
Las condiciones necesarias para que en una sociedad se favorezca la corrupción son tres: el monopolio de un pequeño grupo de servidores públicos en la toma de decisiones, la discresionalidad que algunos servidores tienen para tomar y resolver decisiones de carácter público y, por último, la rendición de cuentas en cuanto a la toma de decisiones, su control y su fiscalización.

La corrupción encontraría su terreno más fértil cuando se toman las decisiones públicas en un régimen de práctico monopolio, ya sea personal, ya sea organizacional, con amplias facultades discrecionales y sin criterios bien delimitados de decisión y, finalmente, sin mecanismos que obliguen a los decisores a rendir cuentas y a responsabilizarse por sus acciones. Mientras que la corrupción se encontraría ante un ambiente mucho más hostil cuando las decisiones son tomadas por un agente plural y de forma consensuada, atendiendo a criterios precisos y objetivos, y abierto a una estricta fiscalización y rendición de cuentas (Artavia, 2008).

El acto corrupto violenta a la larga la democracia, la institucionalidad democrática y el Estado de derecho, pues el funcionario corrupto confunde los roles y la distinción que se ha de dar entre lo público y lo privado. La corrupción acarrea graves consecuencias políticas, económicas y administrativas a un Estado, pues lo debilita y lo hace poco creíble e inmoral y genera apatía e indiferencia de la ciudadanía frente a unos funcionarios corruptos. Por tanto, para combatir la corrupción, se requiere vigilancia y protesta social, cuando sea el caso, hacer cambios profundos y compromisos serios en la formulación y aplicación de leyes anticorrupción que castiguen a los corruptos, que regulen el financiamiento de campañas políticas y asimismo mejorar la calidad de vida de los servidores públicos para que no negocien sobornos o coimas, educar a la población y ejercer la vigilancia social para estar alertas y denunciar la corrupción.

\section{La impunidad}

Sostiene el Centro Regional de Servicios para América Latina y el Caribe (2013) que, "cuando un porcentaje alto de delitos y actos violentos contra la ciudadanía no son investigados, procesados y, en su caso, castigados, se crea una sensación de vulnerabilidad" (p. 36). Ello lleva a la gente a no sentirse con confianza frente al sistema judicial, pues la mayoría de los delitos no se investigan y por tanto quedan irresueltos.

La impunidad puede tener muchas acepciones, pero aquí se definirá como

la inexistencia, de hecho o de derecho, de responsabilidad penal por parte de los autores de violaciones, así como de responsabilidad civil, administrativa o disciplinaria, porque escapan a toda investigación con miras a su inculpación, detención, procesamiento y, en caso de ser reconocidos culpables, condena a penas apropiadas, incluso la indemnización del daño causado a sus víctimas (Gómez, 2008, p. 170). 
La impunidad impide a una sociedad vivir en paz, en justicia, en democracia, y el cumplimiento de los derechos humanos en dicha sociedad. Para luchar contra aquello que imposibilita la impunidad, se ha de vivir la verdad, la justicia y la reparación de las víctimas. Estos son tres derechos fundamentales que se deben potenciar y vivir en toda sociedad y complementarse mutuamente; es decir que un derecho no puede desarrollarse prescindiendo del otro. Reconocer el derecho a la verdad conlleva hacer memoria escribiéndola o dándola a conocer con el fin de no olvidar lo ocurrido y para que no se repitan nunca más sucesos que amenacen o impidan el goce de los derechos humanos.

Por su parte, tanto las víctimas como la sociedad tienen el derecho a conocer la verdad de lo sucedido cuando se hayan violado los derechos humanos. Al conocer la verdad en una sociedad, se inicia procesualmente el perdón y la reconciliación. La verdad en consecuencia es fundamental para que se brinde a la víctima el derecho a la reparación (Gómez, 2008).

El derecho a la justicia requiere que el Estado proporcione los medios necesarios para que se puedan hacer las debidas denuncias, se pueda investigar y enjuiciar a quien ha violado los derechos humanos de una persona o de un colectivo social. El derecho a la justicia demanda del Estado tomar las medidas necesarias para evitar la impunidad cuando se hayan violado los derechos humanos (Gómez, 2008).

Para hacerle frente a la impunidad, también se hace necesario promover el derecho a la reparación de las víctimas que hayan sufrido violaciones de los derechos humanos. Se ha de reconocer que la reparación no podrá evitar las heridas causadas y el dolor sufrido, pero ella desencadena un proceso que va más allá de la celebración de "actos simbólicos" o de la entrega de ciertos beneficios a las víctimas. El derecho a la reparación debe identificar y reconocer a las víctimas y posicionarlas "en el espacio político y social" (Gómez, 2008, pp. 175-176).

$\mathrm{Y}$ es que en los casos de graves violaciones de los derechos humanos y de violencia extrema no solo las víctimas individuales resultan dañadas, sino que es toda la sociedad la que acaba siendo traumatizada. Por ello, el proceso de reparaciones no se tiene que enfocar exclusivamente en las víctimas individuales, sino que también se tiene que dirigir al conjunto de la sociedad, que también necesita un proceso de reparación social (Gómez, 2008).

\section{La tenencia de armas de fuego}

Para De León (2011), la tenencia de armas de fuego ha estado presente en la vida de los centroamericanos por varias décadas, ya sea por las guerras independentistas, las luchas por delimitar los límites fronterizos o por las luchas internas. Según esta autora,

en los últimos años el avance de la situación de narcotráfico en la región y la regionalización del crimen organizado han convertido al istmo en un canal de paso de actos ilícitos tales 
como el contrabando, el tráfico de personas y droga. Estas actividades están acompañadas del uso de armas y del trasiego de las mismas (p. 78).

Los estudios realizados por el Sistema de Integración Centroamericana dan cuenta de que en el territorio centroamericano existen mucho más armas ilegales que legales, y registran 300 ooo armas ilegales por año provenientes solo de los Estados Unidos que ingresan en el territorio.

Las armas ilegales entran a Centroamérica por puntos fronterizos no vigilados, aduanas, puertos y aeropuertos. Ingresan tanto ocultas en equipajes como en vehículos o contenedores e incluso los traficantes las introducen por piezas, lo que hace más difícil que puedan ser detectadas (El Faro, 2015).

A la larga, la tenencia de armas puede ser un factor que facilita la violencia, pues acarrea una serie de actos ilícitos, que, para llevarlos a cabo, requieren el uso de la violencia. Es decir que la posesión de armas puede acelerar la violencia; su posesión sin control alguno debilita el Estado, la democracia, la paz, y genera incertidumbre en la población, pues aumenta la percepción de inseguridad y las tasas de mortalidad.

Como consecuencia de la posesión de armas que "van a parar a manos de grupos dedicados al narcotráfico, a bandas asaltantes de bancos y de robo de vehículos, a pandillas juveniles vinculadas al crimen organizado y a particulares" (De León, 2011, p. 78), la región centroamericana, en especial el Triángulo Norte de esta, registra cifras elevadas y escalofriantes de homicidios que la han convertido en una de las regiones más violentas del mundo.

\section{Las deportaciones hacia Centroamérica}

Se calcula que entre 1998 y 2005 fueron deportados de los Estados Unidos a la región del Triángulo Norte de Centroamérica alrededor de 46 ooo personas pertenecientes a las pandillas, a los cuales se les sumaron alrededor de 200 ooo deportados comunes. Quienes fueron deportados reprodujeron en El Salvador, Guatemala y en Honduras su modo de actuación que habían aprendido en las peligrosas calles de Los Ángeles y en los centros de reclusión y rápidamente muchos de los jóvenes de los países antes mencionados, y que ya estaban asociados en pandillas, se les sumaron (United States Agency for International Development [USAID], 2006).

Las deportaciones significaron el regreso de muchos delincuentes a los que se les responsabiliza de parte de la violencia. Los deportados poseen vínculos fuera de los países en los que viven actualmente y ello ha permitido la internacionalización de las acciones delictivas. Ante esta situación de la escalada de violencia, los países han de invertir los pocos recursos con los que cuentan en planes de prevención, atención y reinserción de esta población. 
Pero las deportaciones se continúan dando en la actualidad. Hoy, muchos que emigran, además de escapar de la pobreza, también necesitan escapar de la violencia y la inseguridad y requieren protección, la cual se les termina negando la mayoría de las veces.

El verdadero éxodo en este momento, sin embargo, viene de México... El Instituto Nacional de Migración de México reveló que 117491 inmigrantes fueron detenidos en México en 2014, más que en cualquier año desde 2007. El 94 \% de los aprehendidos son de Centroamérica, la mayor parte de Honduras, El Salvador y Guatemala... Solo muy pocos migrantes detenidos en México están identificados o eventualmente a muy pocos de ellos se les brindan oportunidades para solicitar protección internacional. Muchos de estos migrantes están siendo deportados en autobús y avión a sus países de origen... Los niños o jóvenes están en riesgo de ser víctimas de la violencia si regresan a sus familias o comunidades. Organizaciones como Casa Alianza pueden proporcionar refugio para unos pocos, pero no hay servicios o protección para la mayoría [La traducción es mía] (Security Assistance Monitor, 2015).

Es decir que la mayoría de los deportados quedan en el limbo: sin ayuda y sin protección por parte del Estado. Vuelven a la situación de la que escaparon y muchos terminan siendo asesinados o emprenden nuevamente el viaje de regreso hacia los Estados Unidos.

\section{Factores asociados a la violencia siguiendo el modelo ecológico propuesto por la OMS}

Aunque hemos señalado ciertos factores sociales, culturales y políticos como los principales generadores de violencia, consideramos que el modelo ecológico es pertinente también para entender la violencia.

Según el modelo ecológico, la violencia es el producto de diversos factores: individuales, relacionales, sociales, culturales y ambientales (OMS, 2002). El primer nivel es el individual y en este se pone la atención en el individuo y en sus características particulares que lo pueden convertir en víctima o en victimario de la violencia. En este nivel, tanto la biología de cada persona como su historia van a influir en la conducta personal, pero también pueden contribuir en el comportamiento de un individuo "factores tales como la impulsividad, el bajo nivel educativo, el abuso de sustancias psicotrópicas y los antecedentes de comportamiento agresivo o de haber sufrido maltrato" (OMS, 2002, p. 14).

El segundo nivel es el de las relaciones, el cual pretende indagar sobre las relaciones cercanas de un individuo con sus familiares, con sus amigos, con su pareja, etc., que lo pueden convertir en víctima o victimario de la violencia. Lo que se plantea en las relaciones es que ellas determinan o configuran la manera en la que una persona se comporta o vive muchas de sus experiencias. 
El tercer nivel es el nivel comunitario y con este se explora el contexto comunitario en el que se desarrollan las actividades y las relaciones sociales, “y busca identificar las características de estos ámbitos que se asocian con ser víctimas o perpetradores de actos violentos" (OMS, 2002, p. 14). Características como el cambio constante de vivienda, la diversidad poblacional, la poca cohesión social o el aislamiento de una persona, una alta tasa de densidad poblacional, el tráfico de drogas y el desempleo pueden hacer mucho más vulnerable a una persona para sufrir la violencia que a otra que vive en contextos con características opuestas a las mencionadas (OMS, 2002). Es decir, ciertos ambientes comunitarios pueden favorecer o no la violencia.

Finalmente, tenemos el nivel social, cuyo objetivo es examinar la manera en la cual los factores sociales pueden determinar la violencia. En este se pueden incluir factores que facilitan un ambiente de aceptación de la violencia, factores que reducen la violencia, que generan tensiones, segmentaciones o separaciones sociales, y los que generan tensiones o conflictos sociales en los diversos grupos que componen una sociedad. También pueden ser generadoras de violencia ciertas políticas estatales, ya sean educativas, de salud, económicas o sociales, que producen desigualdad entre los diversos actores o grupos de una sociedad concreta (OMS, 2002).

\section{Principales actores que generan violencia en el Triángulo Norte de Centroamérica}

Centroamérica tiene una de las tasas de homicidio y violencia criminal más altas no solo de Latinoamérica sino del mundo entero, sus índices de criminalidad superan los de la mayoría de los países, incluso superan a países que están en plena guerra. La violencia se concentra principalmente entre los jóvenes varones, cuyas edades oscilan entre $15 \mathrm{y}$ 34 años. Para contrarrestar esta situación, los Gobiernos de la región invierten grandes sumas de su PIB, con lo cual se pierde ese dinero que pudiera ser destinado al desarrollo, que tanta falta hace en una región empobrecida.

Algunos estudios sobre la violencia sostienen que existe una relación estrecha entre tamaño de la ciudad y las tasas de violencia urbana; sin embargo, hay que ser cautelosos frente a esta afirmación, ya que la escalada de la violencia en la región centroamericana no es tan fácil de explicar. Para Jütersonke, Muggah y Rodgers (2009), la violencia tiene como resultado: "A fragmentation of public space, a proggressive breakdown of social cohesion trough the generation of new forms of spacial segregation and social discrimination, and potentially more violence"3 (p. 4).

La ola de violencia que se vive actualmente en el Triángulo Norte de Centroamérica es causada concretamente por dos grupos criminales organizados: las maras y los

${ }^{3}$ Una fragmentación del espacio público, una ruptura progresiva de la cohesión social a través de la generación de nuevas formas de segregación espacial y discriminación social, y potencialmente más violencia. 
traficantes de droga. Ambos grupos son los actores principales que generan violencia y, además, son los dos grupos que producen desplazamiento en la población, porque desean controlar el territorio y ante esa necesidad han pactado entre ellos.

La idea de ambos grupos es, además, de controlar el territorio, traficar, ya sean drogas, armas de fuego, mercancías o personas. La alianza entre las maras y el crimen organizado ha intensificado los niveles de inseguridad y de violencia, aparte que ejercen control de las autoridades y de las comunidades. "La violencia y los criminales han penetrado todos los aspectos de la vida en Centroamérica, convirtiéndose en los factores primarios que impulsan la migración... desde esa región" (United States Conference of Catholic Bishops, 2013, p. 5). Así es como los altos niveles de violencia en el Triángulo Norte de Centroamérica influyen en el desplazamiento forzado de la población.

\section{Las maras}

Las maras son grupos que se caracterizan por que realizan actividades criminales, tales como tráfico de drogas y extorsión a pequeños negocios y a residentes de las zonas en las que tienen influencia. La extorsión también se aplica a los transportistas, a los vendedores ambulantes, a quienes reciben remesas o ingresos por un trabajo o se aplica cuando la mara percibe deslealtad en una persona. Las maras imponen a la población códigos tácitos de conducta. Las personas pueden ver, escuchar, pero jamás hablar o denunciar lo que pasa bajo el peligro de ser torturados o, en el peor de los casos, asesinados.

Las maras cuentan con el apoyo local de miembros de las familias y de "halcones", que son sus ojos y sus oídos en los barrios. Las maras están muy localizadas en zonas urbanas, pobres y marginales, donde hay poca vigilancia y control del Estado. Cuando los habitantes del barrio no cumplen con los códigos de comportamiento recurren al uso de la violencia contra ellos: "The clikas of the present can be characterised as highly localised and largely urban criminal organizations that swiftly resort to the use of violence against inhabitants"4 (Cantor, 2014).

Las maras son uno de los rostros evidentes de la violencia. El problema de las maras radica en la exclusión que viven muchos jóvenes y la organización en maras es una respuesta a esa situación de exclusión social, económica y política a la cual se ven sometidos. El fenómeno de las maras trasciende las fronteras y se ha convertido en un problema transnacional, ya que los grupos están vinculados internacionalmente.

En un principio, el análisis de las maras se redujo a verlos simplemente como grupos que querían llamar la atención en una sociedad que los excluía (lo cual es cierto) o se les asociaba con jóvenes que robaban y que asaltaban.

\footnotetext{
${ }^{4}$ Las clicas del presente pueden caracterizarse como organizaciones criminales altamente localizadas y en gran parte urbanas que frecuentemente recurren al uso de la violencia contra los habitantes.
} 
Sin embargo, su creciente implicación con grupos de asesinos y traficantes de droga hace pensar que se trata de bandas altamente organizadas, con amplias conexiones internacionales. Las maras han disparado los índices de violencia y crimen organizado en Centroamérica y, además, se han convertido en el emblema de la violencia brutal (Fernández, 2006, p. 63).

Estos grupos han incrementado su accionar delincuencial y han generado con ello nuevos tipos de violencia que actualmente están ligados al crimen organizado transnacional y lograr así que tanto los delitos como la violencia sean mayores. Con el pasar de los años, las maras pasaron de ser defensoras de sus territorios y luchar por ellos a entrar en el negocio del tráfico y venta de drogas, con lo cual han llegado a tener patrones de comportamiento más violentos. "Las maras y pandillas tienden a servir como un aparato de seguridad local para los pequeños cárteles de la droga” (Jütersonke, Muggah y Rodgers, 2009), muchos de los cuales están dirigidos por exmareros.

Jütersonke, Muggah y Rodgers (2009) sostienen que no se conoce con precisión cuál es el número de miembros que forman parte de estos grupos, pero algunos señalan que puede oscilar entre 69000 a 200000 personas. Quizá la escasa y no muy clara información, la falta de datos o la interferencia de la policía en ellos pueden ser la explicación de la falta de precisión en cuanto a los números. Pero algo que se constata es que son muchos más los miembros pertenecientes a las pandillas que los encargados estatales de velar por la seguridad de los ciudadanos de las naciones centroamericanas.

Cabe destacar que las pandillas se manifiestan mucho más en las ciudades que en las áreas rurales y que la mayoría de sus miembros son jóvenes de sexo masculino, aunque no se descarta en ellas la participación de mujeres; la edad promedio de un miembro de una pandilla oscila entre los 20 y 25 años. Sin embargo, se puede decir que la edad es variable, pues puede haber algunos miembros cuya edad mínima es de 12 años y la máxima los 30 años. Los motivos para entrar en las pandillas son variados y van desde la búsqueda de amistades a la evasión de problemas familiares. Muchos sostienen que existe una relación estrecha entre desempleo y pandillas, entre pobreza y participación en estas. Los factores estructurales, como el machismo, la exclusión social, la inequidad, el autoritarismo, el antiguo conflicto armado de los países centroamericanos y la posesión de armas pueden estar ligados con la entrada de muchos jóvenes en las pandillas (Jütersonke, Muggah y Rodgers, 2009).

Jütersonke, Muggah y Rodgers (2009) hacen una distinción entre maras y pandillas. Las maras constituyen un fenómeno con orígenes transnacionales, mientras que las pandillas están más localizadas, son grupos más nacionales. Las maras Dieciocho y Salvatrucha tienen su presencia en Honduras, Guatemala y El Salvador, mientras las pandillas tienen su presencia en Panamá, Costa Rica y Nicaragua. 


\section{Los traficantes centroamericanos}

La criminalidad que se vive en el territorio centroamericano se puede vincular estrechamente con el narcotráfico. El Plan Colombia propuesto por el Gobierno estadounidense pretendía entre uno de sus objetivos contener a los narcotraficantes y para ello militarizó la región de Centroamérica, principalmente el Triángulo Norte de Centroamérica.

Concretamente en Honduras, en 2013, el presidente de los Estados Unidos Barack Obama señaló a los Cachiros como una mafia de mucho cuidar a la que se debía combatir.

En septiembre de 2014 inició la caza y captura de varios de los más señalados mafiosos. Y en enero de 2015 se produjo la entrega de los dos jefes Cachiros en Estados Unidos. O se entregaban o los capturaban y los mataban (Moreno, 2015, p. 35).

Sin embargo, en Honduras, la droga entra en su territorio desde la década de 1970, pero se ve estratégico este país para el tráfico de drogas después de la muerte del gran capo de la droga Pablo Escobar. "Ya a mediados de los 90 la Moskitia, Colón y Olancho se habían convertido en zonas estratégicas para el transporte de cocaína hacia México y Estados Unidos" (Moreno, 2015, p. 37).

Entre los corredores principales de la droga por el territorio hondureño, están el de Colón y el del Atlántico, los cuales están ligados a los carteles colombianos, venezolanos y mexicanos. Esos vínculos existentes entre los carteles y los narcotraficantes, no solo de Honduras sino de casi todo Centroamérica, llevan a que el territorio se haya convertido "en puente aéreo y marítimo en el tránsito de la cocaína entre Colombia, México y Estados Unidos” (p. 37), lo cual ha desatado la guerra y por tanto la muerte entre los traficantes y sus colaboradores para extender su territorio de acción, sus vínculos con los grandes carteles y maximizar sus ganancias.

Los traficantes centroamericanos contrabandean mercancías ilícitas, sobre todo, cocaína; coordinan sus actividades con familias locales y tienen gran poder e influencia social y política. Son grupos sumamente organizados y disciplinados y ejercen gran poder en especial en zonas no urbanas y donde hay poca influencia de las autoridades estatales de seguridad.

El desplazamiento forzado en estas zonas es, por tanto, bastante diferente en forma y en escala del de los territorios donde operan las maras. Mientras que las maras viven de actividades delictivas localizadas en zonas de alta densidad de población, quien transporta drogas se adapta mejor a los lugares menos poblados y periféricos del país, de tal manera que sus respectivas zonas de operación son, por lo general, distintas. Por otra parte, a diferencia de las actividades delictivas de las maras, el negocio del tráfico de drogas no ha dependido históricamente del control exclusivo de estos extensos territorios rurales, 
sino más bien de la capacidad de moverse a través de ellos sin impedimentos. Tradicionalmente, una actitud de vivir y dejar vivir prevaleció entre quienes transportan drogas. Otra distinción es que su relación con la población de estos territorios se basa -en un primer momento al menos- menos en el miedo y la violencia y más en la compra de voluntades de los habitantes y las autoridades. En estas comunidades pobres, trabajar para quienes transportan drogas representa una fuente de ingresos económicos y una ayuda generosa en el suministro de materiales de apoyo para la comunidad. En consecuencia, la población en zonas controladas por los traficantes de droga están menos expuestas a la violencia extrema y la extorsión de las ciudades desordenadas [La traducción es mía] (Cantor, 2014, pp. 8-9).

El desplazamiento forzado en las zonas de influencia de los traficantes es menos persuasivo y está más dirigido a personas concretas que en las zonas influenciadas por las maras.

\section{Incidencia de la violencia en el desplazamiento forzado}

La migración de personas de Centroamérica se ha visto relacionada muchas veces única y exclusivamente a razones de índole económica y en poquísimos casos a temas de reunificación familiar, sin embargo, la migración se la ha relacionado muy poco a la violencia. El énfasis de sus causas se ha puesto más en factores económicos que de la violencia.

Sin embargo, la migración sin acompañantes de niños y niñas hacia los Estados Unidos desveló una realidad que se venía viviendo mucho antes, que actualmente muchas personas y más de las que se piensan se están moviendo debido a la violencia y al crimen organizado. Vogt (2013), que en su trabajo de investigación entrevistó a varios jóvenes migrantes, sostiene que muchos de ellos tuvieron como razón para migrar el miedo y las presiones para entrar en las maras. Manifiesta este autor en dicho estudio que para esos jóvenes, "transnational migration is considered the only way to scape both physical and social death"5 (p. 769).

La violencia es un motor de la migración, pues está incidiendo grandemente en el desplazamiento forzado. Con ello, no queremos o pretendemos negar las otras causas o razones de la migración, pero se hace necesario evidenciar esta realidad que padecen a diario miles de personas en el Triángulo Norte de Centroamérica.

Ese aumento de la violencia ha provocado que mucha gente de la población civil se haya tenido que desplazar forzadamente hacia el interior a lo largo y ancho de estos países, pero también se han desplazado hacia el exterior, con lo cual han generado un movimiento humano que antes se había dado por otras condiciones, pero no por la violencia y el crimen organizado. Las cifras exactas de los desplazados no se conocen, pero es muy probable que aumente en lugar de disminuir, porque no solo se están moviendo

\footnotetext{
${ }^{5}$ La migración transnacional se considera la única manera de escapar de la muerte tanto física y como social.
} 
adultos sino también niños y niñas, y jóvenes menores de 18 años, lo cual ha quedado evidenciado en los últimos acontecimientos con menores de edad hacia los Estados Unidos acaecidos en el segundo semestre de 2014. Esto desnuda una realidad que debe ser atacada y, por tanto, los Gobiernos y las instituciones que trabajan en pro de los derechos humanos de las personas migrantes no pueden quedar de espaldas a esta realidad.

Hoy, la violencia tiene nuevos actores y ello pone de manifiesto lo difícil que se hace enfrentarla. Sin embargo, se ha visto desde la experiencia vivida que no es con mano dura que esto cambiará; no es haciendo una guerra al crimen organizado como esa situación se modificará. En todo caso, esta realidad nos debe llevar a pensar en las víctimas de la violencia y del crimen organizado que al final son las que sufren y las que tienen que salir adelante ante una cruel realidad, que, en muchos casos, les obliga a comenzar una nueva vida.

\section{Formas de desplazamiento forzado}

Los grupos criminales o crimen organizado producen desplazamiento forzado en la población, ya sea el que se da a diario como resultado de sus actividades o el generado por las violentas disputas recurrentes entre los grupos criminales. "From the standpoint of the criminal group, the following broad grounds of displacement may be identified... betrayal or enmity; resistance; land appropriation; and insecurity"6 (Cantor, 2014, p. 12). Veamos a continuación cada uno de esos modos de desplazamiento.

1. Si perciben a la persona enemiga o traidora: todo depende de la visión que tengan los grupos criminales de una persona, esta persona puede ser considerada enemiga o traidora; por ejemplo, si tiene vínculos con familias de otros barrios enemigos o transita por ellos, puede ser declarada enemiga o traidora. Los grupos criminales creen que cualquiera los puede demandar ante las autoridades o traicionar, ya sea revelando información sobre su modo de funcionar, ya sea reconociendo su identidad, algo que les puede acarrear consecuencias negativas para su trabajo.

2. Si la persona se resiste o no a sus demandas, sobre todo, a las demandas de extorsiones sistemáticas llamadas impuestos de guerra en el caso de Honduras o renta en el caso de El Salvador. Cuando la persona no accede a la extorsión o se retrasa en el pago, se recurre al secuestro de algún miembro de la familia como mecanismo de presión para que se pague la extorsión. La persona debe ceder a la extorsión si no pone en peligro su vida.

${ }^{6}$ Desde el punto de vista del grupo criminal, los siguientes motivos de desplazamiento pueden ser identificados... la traición o la enemistad, la resistencia, la apropiación de tierra y la inseguridad. 
Por supuesto, la falta de pago de la extorsión no es el único acto que pueda ser constituido como de "resistencia" a estos grupos. Por ejemplo, el código impuesto por las maras a los habitantes de algunas zonas "centrales" busca erradicar las estructuras de poder alternativas y, por tanto, podrán designar una serie de actividades como de "resistencia". Mucho depende de las circunstancias particulares, pero los actos de resistencia comunes incluyen: jóvenes que se niegan a unirse a las clicas, niñas que rechazan las atenciones de un marero o que se niegan, contestan o miran con recelo a un marero o asistir a una escuela en una zona controlada por la mara opuesta. La forma resultante de la venganza también depende en gran medida de la naturaleza de las clicas locales: mientras que algunas tratan dichas personas e incluso a sus familias como "traidores", otros parecen dejar de observar a la familia después de que el individuo "resistente" ha huido de la zona [La tarducción es mía] (Cantor, 2014, p. 14).

3. Apropiación de tierras: el interés de los grupos criminales por la tierra, sobre todo en zonas rurales, ha ido en aumento tanto en Honduras como en Guatemala. Los traficantes de droga tienen cierto interés por tierras ubicadas en zonas estratégicas para el negocio. En esas tierras, ofrecen a pequeños y medianos campesinos un precio ridículo por ellas y los obligan a desplazarse una vez adquieren las propiedades. Dichas tierras están ubicadas en zonas fronterizas, con poca presencia militar o policial, con poco acceso y muchas veces necesitadas de ayuda económica para el desarrollo de la comunidad. Una vez entran en las tierras o en las comunidades, conquistan a los líderes comunitarios y a la comunidad en general con el patrocinio de actividades u obras de interés social.

Una manifestación urbana de este fenómeno ha aparecido en los últimos años en algunas zonas centrales de maras tanto de Honduras como de El Salvador: mientras que las maras han utilizado durante mucho tiempo las casas abandonadas por las familias desplazadas para sus propios fines, ciertas clicas están empezando a desplazar deliberadamente familias con el fin de hacerse cargo de sus casas situadas estratégicamente. Algunas transacciones se formalizan incluso por abogados traídos por la mara [La traducción es mía] (Cantor, 2014, p. 15).

4. Inseguridad: es derivada del clima de violencia que crean los grupos criminales una vez se asientan en una comunidad determinada. La población donde hay presencia de los criminales teme al futuro, en especial al futuro de los niños y las niñas, que lo más probable es que sean obligados a entrar forzadamente en los grupos mareros, una vez tengan la edad suficiente para su pertenencia. La inseguridad también es generada por la frustración que siente la población por los altos niveles de inseguridad y de criminalidad que se viven en el área donde residen. 
Sin embargo, incluso en este caso, algún evento específico a menudo sirve como disparador para desplazar: la llegada de un grupo criminal al barrio, la eliminación de una estación de policía o el testimonio de un crimen no puede plantear un riesgo inmediato, sino que simplemente sea la última paja en un contexto de por sí difícil. Esta forma de desplazamiento es la más difícil de capturar analíticamente, ya que comprende una serie de temores más o menos remoto. No obstante, el desplazamiento por este motivo es aparentemente generalizado, con derecho preferente en la naturaleza, y tiende a involucrar a las personas y familias en lugar de a comunidades enteras [La tarducción es mía] (Cantor, 2014, p. 16).

Ante ese modo sistemático de generar violencia hacia la población por parte del crimen organizado, la población del Triángulo Norte de Centroamérica está desprotegida, de ahí que sea importante el diálogo con estos grupos, lo cual supone escucharlos y brindarles oportunidades para que salgan de las maras. El Gobierno ha de cambiar de enfoque para buscar una solución al problema de la violencia y de quienes la ejercen. Ha de pasar de la represión y los planes "manos duras" a un enfoque más humano, ya que la implementación de las medidas de los Gobiernos centroamericanos tuvieron consecuencias negativas, pues el remedio fue peor que la enfermedad, dado que, al final, las maras se reorganizaron, se cualificaron mejor y se armaron, con lo cual se volvieron mucho más peligrosas y violentas.

Como se afirmó, las maras como los grupos criminales han obligado a niños, niñas, mujeres, adolescentes y jóvenes a desplazarse forzadamente. Aunque también se señale como causas de las salidas razones económicas o de reunificación familiar, se puede afirmar, desde un estudio realizado por el Alto Comisionado de las Naciones Unidas para los Refugiados (2014, p. 16), que 48.6 \% de niños, de niñas y de adolescentes encuestados señaló la violencia concretada en "golpes, intimidaciones, amenazas e inseguridad" como la causa principal de la salida. Es decir que la violencia actual obliga a una población a huir, por lo que son las razones económicas o la reunificación familiar en la mayoría de los casos consecuencias de las salidas y no sus causas.

\section{Conclusiones}

La violencia que se vive en el territorio centroamericano es alarmante. Ella está provocando una movilización humana tanto interna como externa debido a que en el caso de un significativo número de personas peligra la vida o ella está en juego. La violencia es tal que puede ser considerada una epidemia por la tasa de homicidios por cada 100 ooo habitantes y por tanto la violencia puede considerarse un problema de salud pública que se debe atacar y solucionar por parte de los Estados.

Esa ola de violencia que se vive actualmente en el Triángulo Norte de Centroamérica es causada concretamente por dos grupos criminales organizados: las maras y los traficantes 
de droga. Ambos grupos son los actores principales que generan violencia y desplazamiento en la población, porque desean controlar el territorio y ante esa necesidad han pactado entre ellos, con lo cual se han incrementado los niveles de violencia e inseguridad.

Las maras como los grupos de narcotraficantes han empujado a gran parte de la población a desplazarse forzadamente y, aunque se señale como causas de los desplazamientos las razones económicas o de reunificación familiar, se puede afirmar que la violencia es la principal causa de desplazamiento ya que obliga a muchas personas a desplazarse a nivel interno de los países del Triángulo Norte de Centroamérica como fuera de ellos.

Esa violencia generalizada además del desplazamiento ha generado víctima mortales que quedan reflejadas únicamente en las estadísticas, pero no se les da seguimiento para determinar las causas y los perpetradores de estas. Es decir que en el Triángulo Norte de Centroamérica se evidencia una impunidad ante los homicidios, pues no se identifica y persigue a sus responsables que evidencia una debilidad del sistema judicial y de las autoridades garantes de la seguridad de los ciudadanos, lo cual lleva a las personas a desconfiar de dichas instituciones y a percibir que la inseguridad es parte de su realidad cotidiana.

\section{Referencias}

Acnur (2012). Desplazamiento forzado y necesidades de protección generados por nuevas formas de violencia y criminalidad en Centroamérica. Recuperado de http://www.acnur.org/t3/fileadmin/Documentos/BDL/2012/8932.pdf?view=1

Acnur (2014). Arrancados de raíz. México. Recuperado de http://www.acnur.org/ $\mathrm{t}$ 3/fileadmin/scripts/doc.php?file=t3/fileadmin/Documentos/Publicaciones $/ 2014 / 9828$

Artavia Araya, F. (2008). Decisiones públicas, beneficios privados: consideraciones teóricas en torno a la corrupción. Revista de Ciencias Sociales, 119, 13-26.

Bautista, Ó. D. (2009). Ética para corruptos: una forma de prevenir la corrupción en los gobiernos y las administraciones públicas. Bilbao: Desclée de Brouwer.

Briceño-León, R. (2007). Violencia urbana en América Latina: un modelo sociológico de explicación. Espacio Abierto, 16(3), 541-574.

Cantor, D. J. (2014). The new wave: forced displacement caused by organized crime in Central America and Mexico. Recuperado de http://rsq.oxfordjournals.org/ content/early/2014/o6/10/rsq.hduoo8.full

Cañas, J. S. (s. f.). Los salvadoreños y salvadoreñas evalúan la situación del país a finales de 2013 y opinan sobre las elecciones presidenciales de 2014. Boletín de prensa, 27(2). Recuperado dehttp://www.uca.edu.sv/publica/iudop/archivos/boletin4_2012.pdf 
Cardenal, A. S. (2008). ¿Son las guerras civiles responsables del crimen en Centroamérica? Revista CIDOB d'Afers Internacionals, 81, 67-90.

Centro Regional de Servicios para América Latina y el Caribe (2013). Informe regional de desarrollo humano 2013-2014. Programa de las Naciones Unidas para el Desarrollo.

Comisión de Derechos Humanos de las Naciones Unidas (2005). Principios y directrices básicos sobre el derecho de las víctimas de violaciones manifiestas de las normas internacionales de derechos humanos y de violaciones graves del derecho internacional humanitario a interponer recursos y obtener reparaciones. Recuperado de http://memoriaydignidad.org/memoriaydignidad/index.php/site-administrator/ derechos-humanos-y-dih/instrumentos-internacionales-derechos-humanos-y-dih

Gutiérrez, P., Magdaleno del Río, G. y Yáñez, V. (2010). Violencia, Estado y crimen organizado en México. El Cotidiano, 163(163), 105-114.

De León Escribano, C. R. (2008). Violencia y género en América Latina. Pensamiento Iberoamericano, 2, 71-91.

De León Escribano, C. R. (2011). Tráfico ilícito de armas y municiones: Guatemala y la región centroamericana. URVIO: Revista Latinoamericana de Estudios de Seguridad, 10, 77-92.

El Faro (2015). En Centroamérica el mayor número de armas es ilegal. Recuperado de http://www.elfaro.net/es/201504/internacionales/16913/En-Centroam \%C3 \%A9rica-el-mayor-n \%C3 \%BAmero-de-armas-es-ilegal

Fernández, I. (2006). Violencia social en América Latina. Papeles de Cuestiones Internacionales, 94, 59-66.

Fortuna, M. F. (2012). Brasil en la cooperación regional para la lucha contra la violencia y el crimen organizado. Revista CIDOB d'Afers Internacionals, 97, 117-133.

Gómez, F. (2008). El fenómeno de la impunidad: luces y sombras en América Latina. Pensamiento Iberoamericano, 2, 163-185.

González Luna, F. (2013). Espacialización de la violencia en las ciudades latinoamericanas: una aproximación teórica. Cuadernos de Geografía: Revista Colombiana de Geografía, 22(1), 169-186.

Hiskey, J., Malone, M. y Orcés, D. (2014). Violencia y migración en Centroamérica. Perspectivas desde el Barómetro de las Américas, 101, 1-10.

Jütersonke, O., Muggah, R. y Rodgers, D. (2009). Gangs, urban violence, and security interventions in Central America. Security Dialogue, 40(4-5), 373-397. 
Krug, E. G., Dahlberg, L. L., Mercy, J. A., Zwi, A. B. y Lozano, R. (eds.) (2003). Informe mundial sobre la violencia y la salud. Washington: Organización Panamericana de la Salud.

Machado da Silva, L. A. (2011). Polícia e violência urbana em uma cidade brasileira. Etnográfica. Revista do Centro em Rede de Investigação em Antropologia, 15(1), 67-82.

Moreno, I. (2015). Así terminó el reinado del cartel de los Cachiros. Envío: publicación mensual del Instituto Histórico Centroamericano, 34(396), 35-44.

Naciones Unidas (1985). Declaración sobre los principios fundamentales de justicia para las víctimas de delitos y del abuso de poder. Recuperado de http://www.ohchr. org/SP/ProfessionalInterest/Pages/VictimsOfCrimeAndAbuseOfPower.aspx

Organización Mundial de la Salud (2002). Informe mundial sobre la violencia y la salud. Recuperado de http://www.who.int/violence_injury_prevention/violence/ world_report/es/summary_es.pdf

Riesle González, A. (1999). Dimensiones de la corrupción. Psicología Política, 165.

Reisman, W. M. (1981). ¿Remedios contra la corrupción? (Cohecho, cruzadas y reformas). México: Fondo de Cultura Económica.

Rojas Aravena, F. (2008). Globalización y violencia en América Latina: debilidad estatal, inequidad y crimen organizado inhiben el desarrollo humano. Pensamiento Iberoamericano, 2, 3-36.

Saiz Vélez, J. E., Mantilla Bautista, S. I. y Cárdenas Beltrán, J. M. ${ }^{a}$ (2012). Efectos de la corrupción sobre la criminalidad, el crecimiento económico y la pobreza: una evidencia para seis departamentos de Colombia. Criterio Libre, 16, 43-66.

Security Assistance Monitor (2015). Deported back to limbo: the forced exodus from Mexico. Recuperado de http://securityassistance.org/blog/deported-back-limbo -forced-exodus-mexico

UNAH-IUDPAS, Instituto Universitario de Democracia, Paz y Seguridad (2013). Mortalidad y otros. Observatorio de la Violencia, 28. Recuperado de http://lab.rtve. es/en-el-reino-del-plomo/documentos/documento_10.pdf

United States Agency for International Development (USAID) (2006). Central America and Mexico Gangs Assessment. Recuperado de http://pdf.usaid.gov/pdf_docs/ Pnadg834.pdf

United States Conference of Catholic Bishops (2013). Misión a Centroamérica: viaje a Estados Unidos de menores no acompañados. Recuperado de http://www.usccb. org/about/migration-policy/upload/Mission-To-Central-America-Spanish.pdf 
Universidad Centroamericana José Simeón Cañas, Instituto Universitario de Opinión Pública (2015). Evaluación del país a finales de 2014. Serie de informes, 137. Recuperado dehttp://www.uca.edu.sv/iudop/wp-content/uploads/INFORME-137.pdf

Vogt, W. A. (2013). Crossing Mexico: Structural violence and the commodification of undocumented Central American migrants. American Ethnologist, 4O(4), 764-780. 